\title{
Strategi Perbaikan Kecacatan Produk Menggunakan FMEA dan AHP Untuk Produksi Cut Rag Tobacco
}

\author{
Danis Harianto ${ }^{1^{*}}$, Julianus Hutabarat ${ }^{2}$, Fuad Achmadi ${ }^{3}$ \\ ${ }^{1,2,3}$ Program Studi Magister Teknik Industri, Institut Teknologi Nasional, Malang, 65145, Indonesia \\ *E-mail : hariantodanis@gmail.com
}

\begin{abstract}
Abstrak
CRT (Cut Rag Tobacco) adalah campuran tembakau dengan bahan lain yang nantinya dijadikan isi dari rokok. Keluhanyang dikumpulkan selama Januari-September 2019 didapatkan keluhan terbesar yaitu adanya FM (Foreigh Matter) yang terdapat pada CRT yang diproduksi oleh PT.ABC.Keluhandari konsumen tersebut harus segera ditanggulangi agar kepuasan konsumen terjamin.Untuk mencari keluhan yang prioritasnya tertinggi yang harus segera ditanggulangi digunakan metode FMEA.setelah diketahui prioritas kecacatan yang harus diperbaiki maka untuk pengambilan keputusan menggunakan AHP untuk pengambilan keputusan agar pengambilan keputusan lebih terstruktur dan sesuai target. Dari FMEA didapatkan perbaikan untuk mengurangi FM besek yang terdapat pada raw material rajangan yang digunakan untuk memproduksi rokok kretek. Antisipasi dari proses produksi sendiri sudah ada dengan adanya mesin sorter yang diharapkan bisa menghilangkan besek dari tembakau yang nilainya efektifitas masih dibawah $80 \%$. Oleh karena itu perlu dilakukan perbaikan agar nantinya mesin sorter dapat reject FM besek. Dari hasil pemilihan prioritas perbaikan dan perbandingan setiap kategori perbaikan yaitu efektifitas reject FM Besek, waktu proses, efektifitas rejecttembakau dan biaya. Pemilihan kategori reject FM besek tertinggi dengan 50.11\%, dan nilai tertinggi untuk efektifitas reject FM besek adalah upgrade mesin smart sorter dikarenakan dapat meningkatkan efektifitas reject FM besek sebesar $91.44 \%$.
\end{abstract}

Kata Kunci : AHP, Cut Rag Tobacco, FMEA,Reject.

\section{Pendahuluan}

Primary Manufacturing Department (PMD) adalah sebuah departemen yang memproduksi CRT (Cut Rag Tobacco) atau pembuatan suatu blend (satu jenis campuran tembakau untuk suatu jenis rokok) tembakau yang lengkap dengan filler seperti gagang tembakau yang diproses ulang(stem), cengkeh, flavour serta komponen lain yang digunakan untuk pembuatan sebuah rokok yang pada PT.ABC. Berikut jenis keluhan yang diterima departemen PMD selama januari sampai dengan September 2019:

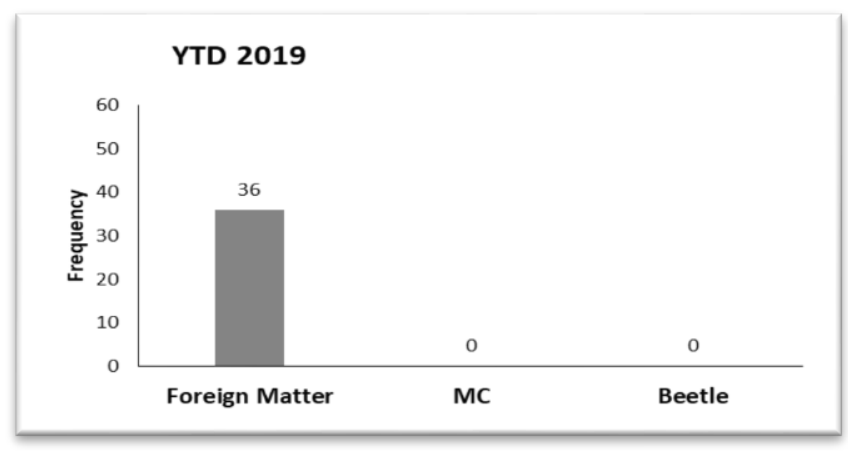

Gambar 1. Data Keluhan Dari Konsumen 
Salah satu metode yang digunakan untuk mencari solusinya adalah dengan menggunakan metode FMEA (Failure Mode and Effect Analysis). FMEA menurut Blanchard (2004) [1][2][3][4][5] merupakan metode analisis induktif untuk mengidentifikasi kerusakan produk dan atau proses yang paling potensial dengan mendeteksi peluang, penyebabnya, efek, dan prioritas perbaikan berdasarkan tingkat kepentingan kerusakan untuk segera ditanggulangi [6][7][8][9]. Analytic Hierarchy Process (AHP) dapat menyelesaikan masalah multikriteria yang kompleks menjadi suatu hirarki. Dengan hirarki, suatu masalah yang kompleks dapat diuraikan ke dalam kelompok-kelompoknya yang kemudian diatur menjadi suatu bentuk hirarki sehingga permasalahan akan tampak lebih terstruktur dan sistematis[10][11].

Tujuan dari penelitian ini adalah Mengetahui dan menganalisis jenis-jenis kecacatan produk yang menjadi keluhan dari konsumen selama Januari-September tahun 2019 yang terbesar pada departemen PMD. Untuk mengetahui jenis kecacatan kritis yang harus segera ditanggulangi departemen ini menggunakan metode FMEA. Menganalisa faktor-faktor yang berpengaruh pada kecacatan produk yang terjadi pada departemenPMD.Menentukan Strategi yang paling efektif untuk menangani terjadinya kecacatan produk yang terjadi di PMD menggunakan AHP.

\section{Metode Penelitian}

Penelitian ini menggunakan instrumen yang terdiri atas data yang disediakan perusahaan, hasil observasi, dan analisa penyebab kecacatan yang terjadi pada departemen[12]. Data ini nantinya digunakan untuk mengetahui perbaikan yang harus dialakukan pada pada departemen PMD untuk mengurangi keluhan dari konsumen.Data sekunder [13][14] pada penelitian ini adalah data yang disediakan oleh pihak perusahaan, baik berupa tabel maupun gambar, dan laporan keluhan dari konsumen, ataupun efektifitas mesin sorter selama ini. Data primer [13][14] adalah data yang didapatkan dari pengamatan, serta melakukan verifikasi terhadap mesin yang menjadi obyek unutk perbaikan kualitas PT. ABC.

\section{Hasil Penelitian dan Pembahasan}

Semua proses uji instrumen dalam penelitian ini dilakukan secara perhitungan manual dengan bantuan Microsoft excel untuk mempermudahkan penghitungan.Dari penelitian yang dilakukan dengan menggunakan data Keluhandari konsumen selama bulan Januari - September 2019 didapatkan hasil yang menunjukan untuk keseluruhan Keluhanberasal dari FM (Foreigh Matter) yang selanjutnya dianalisa agar memudahakan dalam menyunsun prioritas perbaikan bedasarkan type dari FM tersebut. Dari type paling banyak berbahan Organic sebanyak $53 \%$, kemudian Anorganic $33 \%$ dan Syntetic 14\%, Dengan rincian Foreign Matter organic yaitu, Besek, tali, rumput, jerami sebanyak 4 kali, Kertas sebanyak 16 kali, Balok kayu 2 kali, Serpihan kayu sebanyak 1 kali, Lumping tobacco sebayak 2 kali, Lumping Stem sebanyak 1 kali, Gumtape (isolasi kertas) sebanyak 1 kali, Uncut Stem (material stem yang tidak terpotong dengan sempurna) sebanyak 1 kali.

Jumlah FM yang terbesar adalah kertas sebanyak 16 kali, akan tetapi penyebab dari FM tersebut telah diketahui yaitu kertas berasal dari proses trial pada konsumen yang masuk ke dalam wooden crate (tempat packing untuk blend kretek) yang kosong lalu dikembalikan ke PMD, sesampainya di PMD tidak ada pelaksanaan checking wooden crate yang proper sehingga ketika filling tembakau sudah tidak terlihat dan terkirim kembali ke konsumen, untuk menanggulanginya Konsumen diminta memeriksa kembali wooden create sebelum dikembalikan pada departemen PMD dan memberikan label "kosong" pada setiap wooden create yang telah dilakukan pemeriksaan. Foreign Matter kertas yang telah terditeksi darimana asalnya maka status untuk Keluhan tersebut sudah teratasi, oleh karena itu tidak dilanjutkan pada proses selanjutnya. Oleh karena itu jenis FM yang dianalisa selanjutnya tinggal 7 jenis FM, yang selanjutnya dilakukan analisa FMEA untuk menentukan perbaikan prioritas[15]. 
Jurnal Teknologi dan Manajemen Industri, Vol. 6 No. 1, Februari 2020

Pascasarjana Institut Teknologi Nasional Malang

Tabel 3. Penghitungan FMEA Untuk Setiap Nilai Severity, Occurance, Detection serta nilai RPN

\begin{tabular}{|c|c|c|c|c|c|}
\hline No & Jenis FM & Severity & Occurance & Detection & $R P N$ \\
\hline \multirow[b]{2}{*}{1} & \multirow[b]{2}{*}{ Besek } & 7 & 4 & 4 & \multirow[b]{2}{*}{112} \\
\hline & & $\begin{array}{l}\text { Pemilihan nilai high ini } \\
\text { dikarenakan konsumen akan } \\
\text { merasakan adanya penurunan } \\
\text { kualitas yaitu sobek pada rokok } \\
\text { produksi mereka }\end{array}$ & $\begin{array}{l}\text { Pemilihan moderate } \\
\text { dikarenakan terdapat } \\
4 \text { kali keluhan } \\
\text { terkait FM ini }\end{array}$ & $\begin{array}{l}\text { Pemilihan moderate FM ini } \\
\text { dikarenakan memang } \\
\text { terkandung dari Raw } \\
\text { Material sehingga sulit untuk } \\
\text { ditanggulangi meskipun } \\
\text { sudah ada mesin sorter } \\
\text { dengan effektifitas } 75 \%\end{array}$ & \\
\hline \multirow[b]{2}{*}{2} & \multirow[b]{2}{*}{$\begin{array}{c}\text { Balok } \\
\text { kayu }\end{array}$} & 3 & 1 & 1 & \multirow[b]{2}{*}{3} \\
\hline & & $\begin{array}{l}\text { Pemilihan } 3 \text { atau low dikarenakan } \\
\text { bila terdapat kayu balok akan } \\
\text { diketahui sebelum masuk pada } \\
\text { mesin rokok dikarenakan pada } \\
\text { prosesnya material yang berat } \\
\text { akan reject }\end{array}$ & $\begin{array}{l}\text { Pemilihan unlikely } \\
\text { karena hanya terjadi } \\
\text { sekali keluhan } \\
\text { selama } 2019\end{array}$ & $\begin{array}{ll}\text { Pemilihan detection } & \text { very } \\
\text { high dikarenakan pada } \\
\text { departemen PMD } & \text { tidak } \\
\text { menggunakan Balok } & \text { kayu } \\
\text { ataupun pallet dari kayu }\end{array}$ & \\
\hline \multirow[b]{2}{*}{3} & \multirow[b]{2}{*}{$\begin{array}{l}\text { Serpihan } \\
\text { kayu }\end{array}$} & 3 & 1 & 1 & \multirow[b]{2}{*}{3} \\
\hline & & $\begin{array}{l}\text { Pemilihan } 3 \text { atau low dikarenakan } \\
\text { bila terdapar serpihan kayu akan } \\
\text { diketahui sebelum masuk pada } \\
\text { mesin rokok dikarenakan pada } \\
\text { prosesnya material yang berat } \\
\text { akan reject }\end{array}$ & $\begin{array}{l}\text { Pemilihan unlikely } \\
\text { karena hanya terjadi } \\
\text { sekali keluhan } \\
\text { selama } 2019\end{array}$ & $\begin{array}{l}\text { Pemilihan detectionvery high } \\
\text { dikarenakan pada departemen } \\
\text { PMD tidak menggunakan } \\
\text { serpihan kayu ataupun pallet } \\
\text { dari kayu }\end{array}$ & \\
\hline \multirow[b]{2}{*}{4} & \multirow[b]{2}{*}{$\begin{array}{l}\text { Lumping } \\
\text { tobacco }\end{array}$} & 7 & 2 & 3 & \multirow[b]{2}{*}{42} \\
\hline & & $\begin{array}{l}\text { Pemilihan nilai high ini } \\
\text { dikarenakan konsumen akan } \\
\text { merasakan adanya penurunan } \\
\text { kualitas yaitu sobek pada rokok } \\
\text { bila terdapat lumping tobacco }\end{array}$ & $\begin{array}{l}\text { Pemilihan low } \\
\text { dikarenakan terdapat } \\
2 \text { kali keluhan } \\
\text { terkait FM ini }\end{array}$ & $\begin{array}{l}\text { Tobacco lumping disebabkan } \\
\text { oleh penumpukan material } \\
\text { yang menempel pada } \\
\text { cylinder dryer, untuk itu } \\
\text { biasanya satu minggu sekali } \\
\text { akan dilakukan cleaning }\end{array}$ & \\
\hline \multirow[b]{2}{*}{5} & \multirow[b]{2}{*}{$\begin{array}{l}\text { Lumping } \\
\text { Stem }\end{array}$} & 7 & 1 & 3 & \multirow[b]{2}{*}{21} \\
\hline & & $\begin{array}{l}\text { Pemilihan nilai high ini } \\
\text { dikarenakan konsumen akan } \\
\text { merasakan adanya penurunan } \\
\text { kualitas yaitu sobek pada rokok } \\
\text { bila terdapat Lumping Stem }\end{array}$ & $\begin{array}{l}\text { Pemilihan unlikely } \\
\text { karena hanya terjadi } \\
\text { sekali keluhan } \\
\text { selama } 2019\end{array}$ & $\begin{array}{l}\text { lumping stem dikarenakan } \\
\text { pada proses addback terdapat } \\
\text { material stem yang terjepit } \\
\text { pada pojok dan terakumulasi } \\
\text { oleh karena itu setiap habis } 1 \\
\text { blend dilakukan cleaning. }\end{array}$ & \\
\hline \multirow[b]{2}{*}{6} & \multirow[b]{2}{*}{$\begin{array}{l}\text { Gumtape } \\
\text { (isolasi } \\
\text { kertas) }\end{array}$} & 3 & 1 & 1 & \multirow[b]{2}{*}{3} \\
\hline & & $\begin{array}{l}\text { Pemilihan } 3 \text { atau low dikarenakan } \\
\text { bila kayu balok akan diketahui } \\
\text { sebelum masuk pada mesin rokok } \\
\text { dikarenakan material yang berat } \\
\text { akan reject }\end{array}$ & $\begin{array}{l}\text { Pemilihan unlikely } \\
\text { karena hanya terjadi } \\
\text { sekali keluhan } \\
\text { selama } 2019\end{array}$ & $\begin{array}{l}\text { pemilihandetection very high } \\
\text { dikarenakan pada departemen } \\
\text { PMD tidak menggunakan } \\
\text { Gumetape diproses produksi. }\end{array}$ & \\
\hline \multirow[b]{2}{*}{7} & \multirow[b]{2}{*}{$\begin{array}{l}\text { Uncut } \\
\text { Stem }\end{array}$} & 7 & 1 & 1 & \multirow[b]{2}{*}{7} \\
\hline & & $\begin{array}{l}\text { Pemilihan nilai high ini } \\
\text { dikarenakan konsumen akan } \\
\text { merasakan adanya penurunan } \\
\text { kualitas yaitu sobek pada rokok } \\
\text { bila terdapat uncut Stem }\end{array}$ & 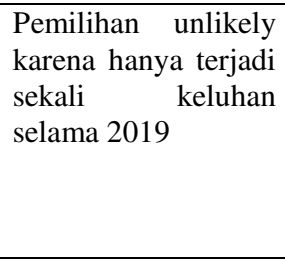 & $\begin{array}{l}\text { pemilihan very } \\
\text { dikarenakan material } \\
\text { melalui proses cutting } \\
\text { dirajang ketika lolos pun } \\
\text { seharusnya tidak ikut pada } \\
\text { proses selanjutnya karena ada } \\
\text { airlock }\end{array}$ & \\
\hline
\end{tabular}

Dari analisa FMEA tersebut didapatkan nilai prioritas tertinggi untuk dilakukan perbaikan yaitu terkait FM dari besek dengan nilai RPN 112, kemudian tobacco lumping 42, kemudian lumping stem 21, uncut stem 7, terakhir balok kayu, serpihan kayu, gumtape 3. Hasil tersebut menempatkan untuk penanggulangan FM besek terlebih dahulu dikarenakan mempunyai nilai RPN terbesar[16][17][18]. Penggunaan material besek ini ini sudah menjadi tradisi pada masyarakat Madura untuk menyimpan tembakau rajangan yang sulit dihilangkan ataupun dirubah. Rasa dan aroma yang khas tembakau ini yang tidak terdapat pada tembakau daerah lain, hal ini membuat tembakau rajangan madura menjadi 
incaran produsen rokok diseluruh Indonesia. Perusahaan harus menerima apa adanya dari petani atau tidak mendapat pasokan tembakau tersebut bila perusahaan meminta petani menggunakan tempat lain untuk menyimpan tembakau mereka.

Setelah ditemukan hasil untuk prioritas keluhan konsumen yang harus segera ditangani dengan melihat RPN tertinggi, setelah itu dilanjutkan untuk pemilihan alternative perbaikan yang bosa dilakukan oleh perusahaan.Untuk mempermudah dalam melihat alternatif dan kriteria untuk perbaikan maka dibuat struktur hierarki yang diawali dengan tujuan umum, dilanjutkan dengan kriteria-kriteria dan alternatifalternatif pilihan [19].
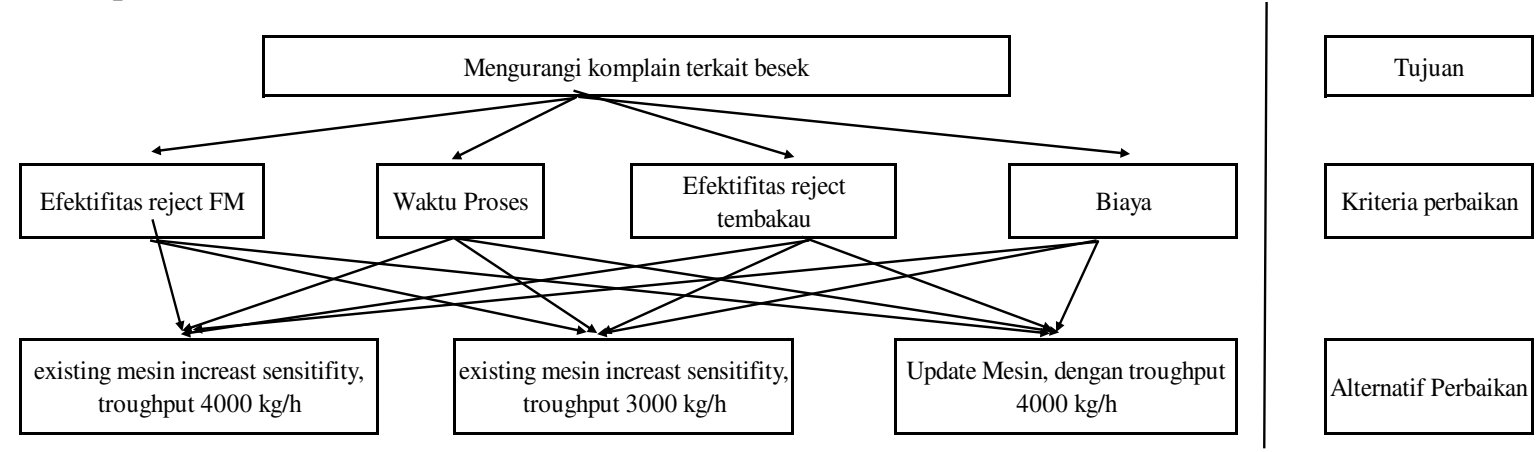

Gambar 2. Hirarki Pemilihan Perbaikan

Dari hirarki diatas ada 3 alternatif perbaikan dan ada 4 atribut yang berpengaruh terhadap perbaikan tersebut. Pilihan untuk perbaikan harus dipilih bedasarkan kepentingan perusahaan. Untuk mengetahui hasil perbaikan nantinya dikakukan verifikasi mesin sorter dengan 3 jenis alternative perbaikan.

Tabel 4. Penyederhanaan Pengambilan Keputusan Antar Perlakukan Perbaikan

\begin{tabular}{|c|c|c|c|c|c|}
\hline & & $\begin{array}{c}\text { Eff reject FM } \\
\text { Besek }\end{array}$ & Waktu proses & $\begin{array}{l}\text { Eff reject } \\
\text { tembakau }\end{array}$ & Kerugian biaya \\
\hline Troughtput $4000 \mathrm{~kg} / \mathrm{h}$ & $\begin{array}{l}\text { Average }(\mathrm{EFF} \%) \\
\mathrm{SD} \\
\text { Max } \\
\text { Min }\end{array}$ & $\begin{array}{c}79.42 \% \\
1.28 \% \\
81.33 \% \\
77.33 \%\end{array}$ & $\begin{array}{l}\text { Satu Blend memakan } \\
\text { waktu } 1 \text { jam } 36 \text { menit }\end{array}$ & $\begin{array}{l}2.42 \% \\
0.63 \% \\
3.43 \% \\
1.56 \%\end{array}$ & $\begin{array}{c}\text { Biaya proses produksi } \\
\text { lebih Rendah dan tidak } \\
\text { ada biaya perbaikan }\end{array}$ \\
\hline Troughtput $3000 \mathrm{~kg} / \mathrm{h}$ & $\begin{array}{l}\text { Average }(\mathrm{EFF} \%) \\
\mathrm{SD} \\
\text { Max } \\
\text { Min }\end{array}$ & $\begin{array}{c}85.17 \% \\
4.00 \% \\
92.00 \% \\
80.00 \%\end{array}$ & $\begin{array}{c}\text { Satu blend memakan } \\
\text { waktu } 2 \text { jam } 8 \text { menit }\end{array}$ & $\begin{array}{l}2.34 \% \\
0.45 \% \\
2.86 \% \\
1.69 \%\end{array}$ & $\begin{array}{l}\text { Biaya proses produksi } \\
\text { lebih tinggi karena proses } \\
\text { produksi lambat dan } \\
\text { tidak ada biaya perbaikan }\end{array}$ \\
\hline TOMRA (Smart Sorter) & $\begin{array}{l}\text { Average }(\mathrm{EFF} \%) \\
\text { SD } \\
\text { Max } \\
\text { Min }\end{array}$ & $\begin{array}{c}91.44 \% \\
2.7 \% \\
93.3 \% \\
87.3 \%\end{array}$ & $\begin{array}{c}\text { Satu blend memakan } \\
\text { waktu } 1 \text { jam } 36 \text { menit } \\
\text { (kemungkinan bisa } \\
\text { dinaikan) }\end{array}$ & $\begin{array}{l}3.3 \% \\
0.7 \% \\
4.0 \% \\
2.4 \%\end{array}$ & $\begin{array}{l}\text { Biaya proses produksi } \\
\text { lebih Rendah dan ada } \\
\text { biaya perbaikan sebesar } \\
35.000 \text { pounds }\end{array}$ \\
\hline
\end{tabular}

Dari hasil perbandingan pada Tabel 4 kemudian manager planakan memberikan bobot terkait kategori perbaikan yang akan dipilih dengan nilai sebagai berikut:

Tabel 5. Pembobotan Antar Keriteria Perbaikan

\begin{tabular}{ll}
\hline No & \multicolumn{1}{c}{ Penetapan Bobot Antar Kriteria } \\
\hline 1 & Reject $\mathrm{FM}:$ Waktu proses $=3$, Reject $\mathrm{FM}$ agak lebih penting dari pada Waktu proses \\
2 & Reject $\mathrm{FM}:$ Reject Tobacco $=5$, Reject $\mathrm{FM}$ cukup penting dari reject tembakau \\
3 & Reject $\mathrm{FM}$ : Biaya perbaikan $=3$, Reject FM agak lebih penting dari pada Waktu proses \\
4 & Waktu proses : Reject Tobacco $=3$, Waktu proses lebih penting dari padareject tembakau \\
5 & Waktu proses : biaya perbaikan $=3$, Waktu proses lebih penting dari pada biaya perbaikan \\
\hline
\end{tabular}


6 Biaya perbaikan : Reject Tobacco $=3$, Biaya perbaikan lebih penting dari pada reject tembakau

Pemilihan kriteria dari perhitungan Tabel 5 dapat disederhanakan seperti Tabel 6:

Tabel 6. Pemilihan Kriteria Untuk Perbaikan

\begin{tabular}{lc}
\hline \multicolumn{1}{c}{ Kriteria } & Bobot prioritas \\
\hline Eigen vector efektifitas mesin sorter & $50.11 \%$ \\
Eigen vector waktu proses & $26.30 \%$ \\
Eigen vector efektifitas reject tembakau & $7.68 \%$ \\
Eigen vector biaya & $15.91 \%$ \\
\hline
\end{tabular}

Mengefektifitaskan mesin sorter untuk mereject FM besek > 50\%, dan setelah dilakukan perhitungan nilai CR = 0,0931 Karena CR (Rasio Konsistensi) < 0,100 [20][21] maka hasil konsisten, maka dipilih untuk perbaikan dengan nilai efektifitas mesin sorter yang tertinggi dari alternative perbaikan yang telah dilakukan diatas sebagai berikut:

Tabel 7. Prioritas Alternative Perbaikan Dari Keriteria Efektifitas Mesin Sorter

\begin{tabular}{lc}
\hline \multicolumn{1}{c}{ Alternatif Perbaikan } & Prosentase Pemilihan Prioritas \\
\hline Troughtput $4000 \mathrm{~kg} / \mathrm{hr}$ & $7.38 \%$ \\
Truoghput $3000 \mathrm{~kg} / \mathrm{hr}$ & $28.28 \%$ \\
Smart sorter tomra & $64.34 \%$ \\
\hline
\end{tabular}

Dari Tabel 7 maka untuk pemilihan perbaikan yaitu dengan update mesin Smartsorter dengan bobot $64,34 \%$ yang menjadi alternatifperbaikan[22].

\section{Kesimpulan}

Jenis FM yang menjadi keluhan dari konsumen yaitu besek sebanyak 4 kali, kertas sebanyak 16 kali, balok kayu 2 kali, serpihan kayu sebanyak 1 kali, lumping tobacco sebayak 2 kali, lumping Stem sebanyak 1 kali, gumtape (isolasi kertas) sebanyak 1 kali, uncut stem (material stem yang tidak terpotong dengan sempurna) sebanyak 1 kali.Untuk keluhan terbanyak adalah adanya kertas sebanyak 16 kali, tetapi untuk jenis tersebut sudah diketahui penyebabnya, oleh karena itu peneliti tidak mengikutkan keluhan tersebut untuk dijadikan prioritas perbaikan.Setelah dilakukan analisa FMEA didapatkan untuk nilai RPN terbesar adalah terkait FM besek dengan nilai 112.

Analisa faktor yang menyebabkan kecacatan produk ini dikarenakan besek menjadi tempat untuk mengumpulkan tembakau rajangan setelah dipotong dan petani dari Madura melakukan hal tersebut sebagai tradisi yang sulit untuk dirubah. Perusahaan tidak bisa memaksa petani untuk menggunakan tempat lain dikarenakan perusahaan lain menerima tembakau ini apa adanya, disamping itu tembakau Madura sangat khas yang menjadi incaran semua pabrik rokok di Indonesia.

Pemilihan alternative perbaikan menggunkan AHP didapatkan untuk kriteria yang menjadi prioritas terpilih adalah efektifitas mesin sorter untuk mereject tembakau dengan 50.11. Kemudain setelah dilakukan verifikasi pada mesin sorter didapatkan hasil alternative perbaikan dengan Update mesin sorter menjadi smartsorter dengan nilai efektifitas reject FM 64.34\% dari alternative lainnya.

\section{Daftar Pustaka}

[1] Ennouri, W. 2015. Risk Management Applying FMEA-STEG Case Study. Polish Jurnal Of Management Studies, Vol 1,No 1: pp 56-67.

[2] Sari, D.P, Marpaung, K.F, Calvin, T, Mellysa dan Naniek U. Handayani. 2018. Analisis Penyebab Cacat Menggunakan Metode FMEA dan FTA Pada Departemen Final Sanding PT Embako Nusantara. Fakultas Teknik Universitas Wahid Hasyim. Prosiding SNST Vol 9, No 9: hal 978-602. 
[3] Irawan, J.P, Santoso, I, dan Mustaniroh, S.A, 2017. Model Analisis dan Strategi Mitigasi Risiko Produksi Keripik Tempe. Industria: Jurnal Teknologi dan Manajemen Agroindustri, University of Brawijaya. Vol 6, No 2: hal 88-96.

[4] Adianto,H, Mayangsari, D. F, \& Yuniati, Y. 2015. Usulan Pengendalian Kualitas Produk Isalator dengan Metode Failure Mode and Effect (FMEA) dan Fault Tree Analysis (FTA): Jurnal Online Institut Teknologi Nasional. Vol 3, No 2: hal 81 - 91.

[5] Iswanto, A., Rambe, A., Jabbar M., dan Ginting, E. 2015. Aplikasi metode Taguchi Analysis dan Failure Mode and Effect Analysis (FMEA) untuk perbaikan kualitas produk di PT. XYZ.e-Jurnal Teknik Industri USU. Vol 2, No 2: hal 13-18.

[6] D.H. Stamatis. 1995. Failure Mode and Effect Analysis: FMEA from Theory to Execution, Milwauke: ASQC Quality.

[7] Chanamool, N. and Naenna, T. 2016. Fuzzy FMEA application to improve decision-making process in an emergency departemen,Applied Soft Computing,Vol.43: pp 441-453.

[8] Dag'suyu, C., Göçmen, E., Narl1, M. and Kokangül, A. 2016. "Classical and fuzzy FMEA risk analysis inasterilizationunit",ComputersandIndustrial Engineering,Vol 101: pp286-294.

[9] Aslani, R.K. 2015. "A hybrid of fuzzy FMEA-AHP to determine factors affecting alternator failure causes",Management Science Letters,Vol.4 : pp 1981-1984.

[10] Nurani, A.I, Pramudyaningrum, A.T, Fadhila, S.R, Sangaji, S, Hartono, W. 2017. Analytical Hierarchy Process (AHP), Fuzzy AHP, and TOPSIS for Determining Bridge Maintenance Priority Scale in Banjarsari, Surakarta.International Journal of Science and Applied Science: Conference Series, Vol 2 No. 1: pp 60-71.

[11] Irawan J.P, Santoso I., Mustaniroh S.A. 2017.Model analisis dan Strategi Mitigasi Risiko Produksi Kripik Tempe. Industria: Jurnal Teknologi dan Manajemen Agroindustri Volume 6 No 2: hal 88-96.

[12] Gasperz, Vincent 2001.Total Quality Manajemen. PT Gramedia : Jakarta.

[13] Arikunto, Suharsimi. 2006. Metodelogi Penelitian, Yogyakarta: Bina Aksara.

[14] Wignjosoebroto, Sritomo. 2003. Pengantar Teknik \& Manajemen Industri Edisi Pertama. Penerbit: Guna Widya. Surabaya.

[15] Darmanto, E, Latifa N dan Susanti N. 2015. Penerapan Metode AHP (Analithic Hirarchy Proses) Untuk menentukan Kualitas Gula Tumbu.Jurnal SIMETRIS, Vol 5, No 1: hal 22-52.

[16] Saaty, T.L. 1980.“The Analytic Hierarchy Process”, McGraw-Hill, New York.

[17] Saaty, T.L. 1994."Fundamentals of Decision Making and Priority Theory with the Analytic Hierarchy Process", RWS Publications, Pittsburgh.

[18] Nursanti, E, Sibut, Hutabarat, J, Septiawan, A. 2018.Risk Management In Subsea Pipelines Construction Project Using Delphi Method, FMECA, and Continous Improvement. ARPN Journal of Engineering and Applied Sciences, Vol 13 No. 11: pp 3834-3838.

[19] Santoso, D. and Besral, A.M. 2018. Supplier Performance Assessment using Analytical Hierarchy Process Method. SINERGI. Vol 22 No 1: pp 37-44.

[20] Butdee, S., Phuangsalee, P. 2019. Uncertain risk assessment modelling for bus body manufacturing supply chain using AHP and fuzzy AHP, Procedia Manufacturing, Vol 30: pp 663-670.

[21] Sahar Mohammad, A.M, Jose Eduardo, M.H, Mohammad Khurshid, K. 2018. Hybrid Framework of, EWGM-FMEA, Analytical Hierarchy Process and Risk Balance Score Card for Risks Assessment in Energy Sector, International Journal of Engineering Management, Vol 2 No 3: pp 58-66.

[22] Handoko,F, Nursanti, E, Harmanto, D, Sutrisno. 2016. The Role of Tacit and Condified Knowledge Within Technology Transfer Program on Technology. ARPN Journal of Engineering and Applied Sciences, Vol 13 No. 11: pp 3834-3838. 